\title{
Comparative Cytogenetic Studies in Alopatric Populations of Trichomycterus paolence Eigenmann, 1918 from South- eastern Brazil (Siluriformes, Trichomycteridae)
}

\author{
R. A. Torres, F. Foresti and C. Oliveira \\ Departamento de Morfologia, Instituto de Biociências, UNESP, Campus de Botucatu, \\ 186i8-000, Botucatu, SP, Brazil \\ Accepted December 15, 1997
}

\begin{abstract}
Summary The karyotypic study of 33 specimens of geographic isolated populations of Trichomycterus paolence (Eigenmann 1918) collected from three brook streams revealed a modal diploid number of 54 and three different chromosomal formula: 44 metacentrics $(\mathrm{M})+8$ submetacentrics $(\mathrm{SM})+2$ subtelocentrics $(\mathrm{ST}), 40$ metacentrics $(\mathrm{M})+14$ submetacentrics $(\mathrm{SM})$, and 46 metacentrics (M) +6 submetacentrics ( $\mathrm{SM})+2$ subtelocentrics (ST). The nucleolar organizer regions (NORs) were interstitially located on the long arms of the same largest submetacentric chromosome pair in the karyotypes in two of three samples analyzed; in the third sample, the NORs were also interstitially located on the long arm as well, but in the largest metacentric pair of chromosomes. C-banding analysis showed centromeric and pericentromeric patterns of DNA heterochromatinization only in a few chromosome pairs in all three populations analysed. Differences in chromosome and karyotype organization among the individuals can constitute interesting markers for specific populations and play its role in the process of diversification within this group.
\end{abstract}

Key words Cytogenetics in Trichomycterus, Chromosome banding, Trichomycteridae.

Trichomycteridae is a typical South American freshwater fish family which includes eight subfamilies (Copionodontinae, Trichogeninae, Trichomycterinae, Glanapteriginae, Sarcoglanidinae, Tridentinae, Stegophilinae and Vandellinae) with about 37 genera and 156 species (Nelson 1994, Burguess 1989) and are characterized by advanced traits within the Siluriformes group (Baskin 1973). The species belonging to this taxonomic family include a series of small-size catfishes characterized by diversified life habits. They are commonly found in the Amazon region where some species live in headwater environments, under leaves and stones, or in a parasitic form. They are also characterized by the absence of the adipose fin and posterior position of the dorsal fin (Eigenmann 1918).

Trichomycterus is a genus with the largest number of species in this family, with probably more than 75 species widely spread in South America from the Atlantic coast to the Pacific and in the Andes region where they reach locations at $4500 \mathrm{~m}$ altitude. Eigenmann (1918) observed that the species of this genus differ in terms of tooth shape, barbel length, relative position of dorsal, ventral and anal fins, and color patterns.

The first karyotypic data obtained for this fish group were described by Arratia and Veloso (1980) in Trichomycterus laucaensis $(2 \mathrm{n}=62$-with subtelocentric chromosomes and microchromosomes), Trichomycterus areolatus $(2 \mathrm{n}=56$ - with metacentric and submetacentric chromosomes), Hatcheria macrei $(2 \mathrm{n}=52$ - with metacentric, submetacentric and subtelocentric chromosomes and microchromosomes) and Bullockia maldonadoi $(2 \mathrm{n}=60$-with metacentric and submetacentric chromosomes). Lima and Galetti Jr. (1990) described the karyotypic structure, number and position of the nucleolar organizer regions (NORs) and the patterns of constitutive heterochro-

Send correspondence to R. A. Torres. 
matin in Trichogenes longipinnis $(2 \mathrm{n}=54$ - with metacentric, submetacentric and subtelocentric chromosomes) and Gonzo et al. (1996) performed cytogenetic studies on Trichomycterus spegazzi$n i$ which presented $2 \mathrm{n}=54$ (with metacentric and submetacentric chromosomes), as well as some specific chromosomal features.

In the present study we analyzed the karyotypes and the chromosome formulae of three alopatric populations of Trichomycterus paolence collected in different river basins in the State of São Paulo, Southeastern Brazil. Cytogenetic analysis were performed in order to better understand the role of karyotype and chromosome modifications and its association to morphological divergences detected by Caramaschi (1986) in the process of species differenciation in this group of fishes.

\section{Materials and methods}

Thirty-three specimens of Trichomycterus paolence, belonging to three different populations were collected and analyzed cytogenetically: eight specimens ( 6 males and 2 females) from Capivara river (Botucatu, SP), a tributary of the left bank of the Tietê river, thirteen specimens ( 5 males and 8 females) from a small stream, Jacutinga (Bofete, SP), also a tributary of the left bank of the Tietê river, and twelve (4 males and 8 females) specimens from Quinta stream (Itatinga, SP), a small tributary of the left bank of the Paranapanema river.

The chromosomes and karyotypes were studied by the standard cell suspension method as described by Foresti et al. (1981), slightly modified, using kidney and gill cells. The nucleolar organizer regions (NORs) were identified by the colloidal silver method (Howell and Black 1980) and constitutive heterochromatin distribution was visualized by the C-banding method of Sumner (1972). The different karyotypes identified were classified as cytotype A, cytotype B and cytotype $\mathrm{C}$, corresponding to the populations already cited, for a better description and discussion of data.

\section{Results}

In the analysis of 6 males and 2 females from the Capivara river population, a diploid number of 54 chromosomes was identified in $74.86 \%$ of 183 metaphases observed. The chromosome formula detected in these specimens was 44 metacentric $(M)+8$ submetacentric $(\mathrm{SM})+2$ subtelocentric (ST) chromosomes and no numerical or structural differences were observed between the sexes (Cytotype A-Fig. 1). The NOR was identified in the interstitial region of the long arm in the subterminal portion of a single chromosome pair which corresponded to the first one in size in the submetacentric group (Fig. 1, in detail). Three chromosome pairs showed well characterized C-banded blocks, which were located in the pericentromeric region in two of them (pairs 23, 24) and throughout the entire the short arm in one (pair 2) (Fig. 4a).

The analysis of 5 males and 8 females from the Jacutinga stream population revealed that $84.57 \%$ of 174 metaphases corresponded to a diploid number of 54 chromosomes, with a formula of 40 metacentric (M) +14 submetacentric (SM). No karyotypic differences were detected between the sexes (Cytotype B-Fig. 2). The NOR was identified in the interstitial region of the long arm in one chromosome pair which corresponded to the first one in size in the submetacentric group, in a similar position as observed in the cytotype A (see detail in Fig. 2). The C-banding technique revealed small heterochromatic blocks in the centromeric position in pairs 1, 2, 3, 23 and 24 and in the pericentromeric position in pairs 21 and 22 (Fig. 4b).

In the sample from Quinta stream population (4 males and 8 females), $66.5 \%$ of a total of 206 metaphases analyzed presented a diploid number of 54 chromosomes. The observed karyotypic formula was 46 metacentric (M) +6 submetacentric (SM) + 2 subtelocentric (ST) chromosomes (Cytotype C-Fig. 3). The NOR was identified in the interstitial region in the long arm of one chromo- 
a
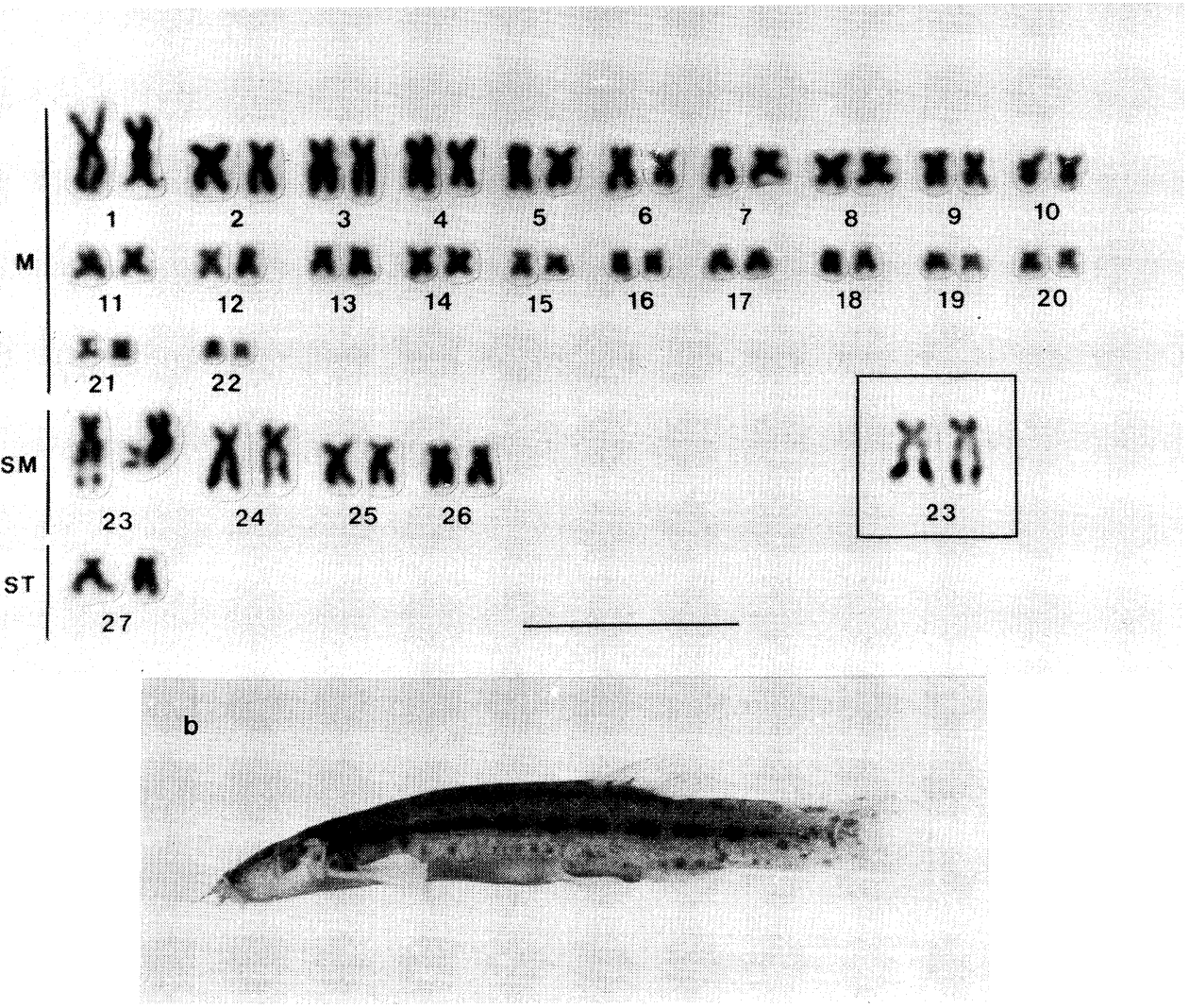

Fig. 1. Trichomycterus paolence, cytotype A $(2 n=54)$. a) Karyotype of a Capivara river specimen (Botucatu, SP) with the NOR banding shown in detail; note the constriction in the long arm of the NORbearing chromosomes (pair 23). b) Seven-cm long specimen. Scale bar $=10 \mu \mathrm{m}$.

some pair which corresponded to the first one in size in the submetacentric group (see detail in Fig. 3). Only six chromosome pairs presented well characterized heterochromatic bands: 1, 2, 5 and 25 with small pericentromeric blocks, pair 26 with heterochromatin located in the centromeric region, and pair 24 with small interstitial blocks in the long arm (Fig. 4c).

\section{Discussion}

Many species of neotropical fishes characteristically present high chromosome variability at both the interspecific and intraspecific level (Almeida-Toledo et al. 1993). Nevertheless, some groups are extremely conservative concerning chromosome number and karyotypic formula. This conservatism or variability have been associated to peculiar population structures. Species belonging to the groups of wide distribution, frequently show highly stable and conservative karyotypes while species organized into small populations and having limited areas of distribution are normally characterized by variable karyotypes (Oliveira et al. 1988).

The cytogenetic studies in Trichomycteridae have revealed a macrostructural conservatism pattern in their karyotypes. Based on chromosomal studies in Trichogenes longipinnis, Lima and Galetti Jr. (1990) suggested the occurrence of a karyotypic stability in this taxonomic family.

In the present study the karyotypic macrostructure in three different populations of Trichomycterus paolence previously considered by Caramaschi (1986) as possibly new species was performed. All karyotypes presented 54 chromosomes, with a predominance of metacentric pairs, fol- 


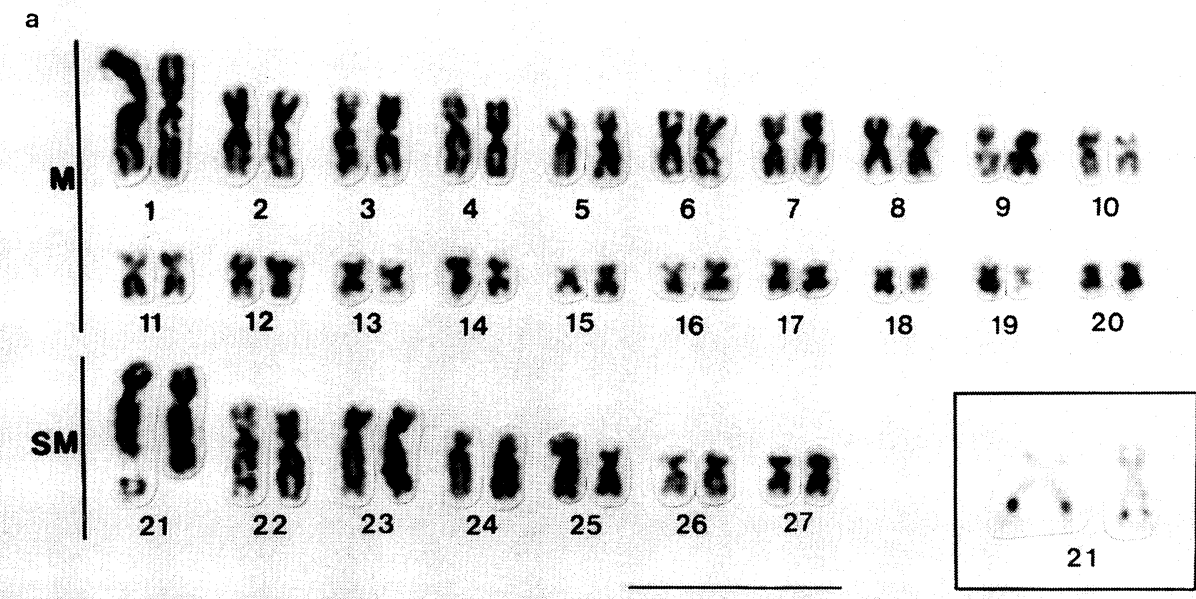

b

Fig. 2. Trichomycterus paolence, cytotype B $(2 n=54)$. a) Karyotype of a Jacutinga river specimen (Botucatu, SP) with the NOR banding shown in detail; note the constriction in the long arm of the NORbearing chromosomes (pair 21). b) Eight-cm long specimen. Scale bar $=10 \mu \mathrm{m}$.

lowed by submetacentric and subtelocentric pairs. Acrocentric chromosomes were not found in the cytotypes. This situation seems to be common to several species in the order Siluriformes (Lima and Galetti Jr. 1990).

The analysis of the karyotypic formulae in the three populations of Trichomycterus paolence showed that the presence of metacentric and submetacentric chromosomes is a constant feature in their karyotypes, with subtelocentric pairs also occurring in two of the three populations analyzed. The occurrence of subtelocentric pairs was possibly produced by deletions along the short arm of submetacentric pairs or by pericentric inversions involving the elements of the same chromosome pair. It was also observed that, besides the general macrostructural similarity found in the karyotypes of the three populations, the chromosome types were extremely variable. Such karyotype variability suggests that chromosomal rearrangements seem to have played a fundamental rolc in the karyotipical diversity among the populations. The typical ecologic population structure found in this species, which is characterized by small groups highly adapted to specific habitats (Caramaschi 1986), supports the idea of a fast fixative process of chromosomal rearrangements. A similar situation was observed by Andreata et al. (1994) in Microlepdogaster sp. A (Alambari river, Botucatu, state of São Paulo) with a karyotypic formula of 30 metacentric (M)+20 submetacentric (SM)+4 subtelocentric (ST) chromosomes, and in Microlepdogaster sp. B (Móia stream, Penápolis, state of São Paulo) with a karyotypic formula of 22 metacentric (M) +28 submetacentric (SM) +4 subtelocentric (ST) chromosomes. The diversity of karyotypes found in these species was also attributed to the particular condition of isolation which characterizes the local populations and permitted the fixation of the different chromosome rearrangements.

Based on chromosome number, a close relationship between Trichomycterus areolatus, Tri- 


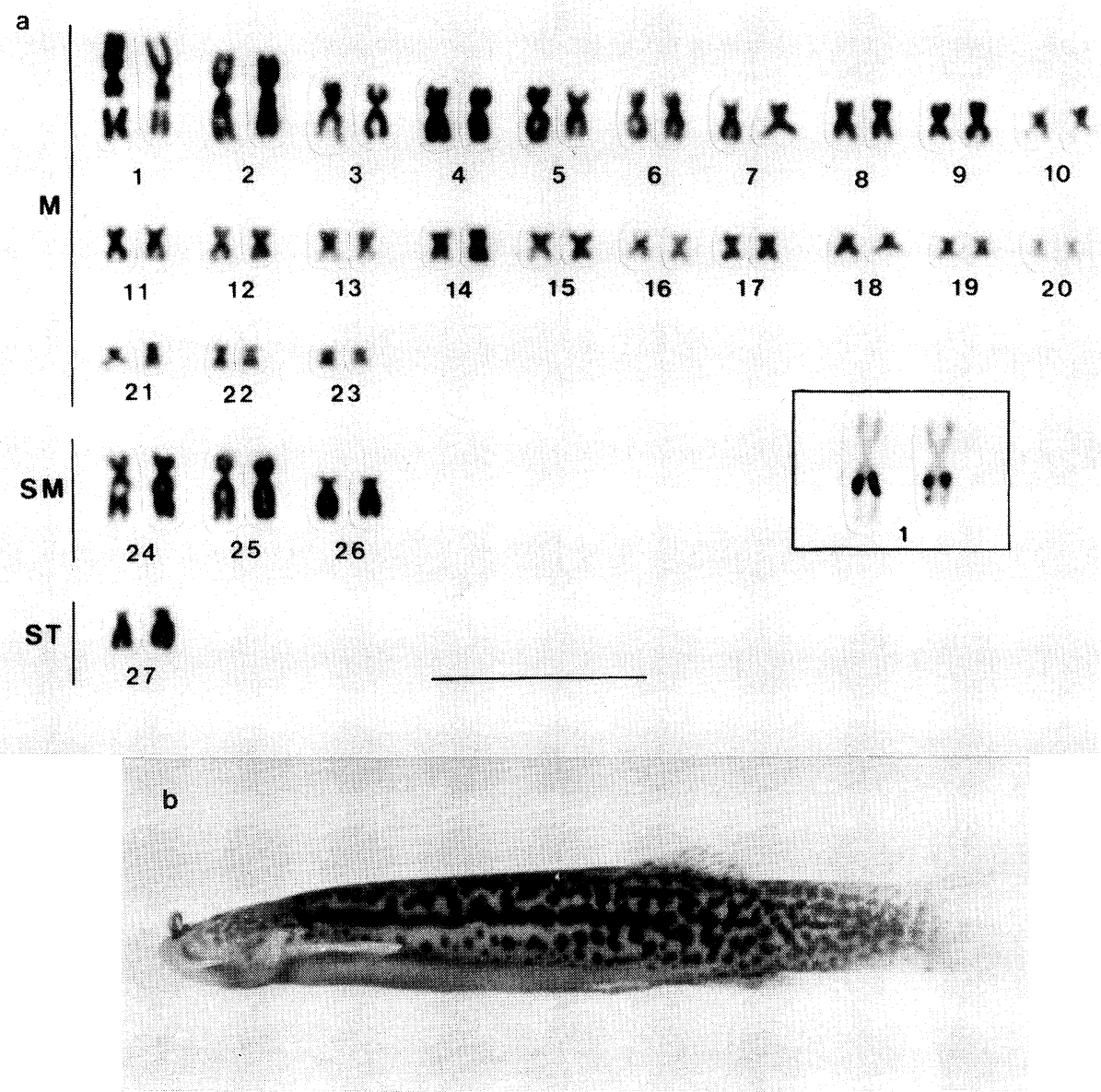

Fig. 3. Trichomycterus paolence, cytotype C $(2 n=54)$. a) Karyotype of a Quinta stream specimen (Itatinga, SP) with the NOR banding shown in detail; note the constriction in the long arm of the NORbearing chromosomes (pair 1). b) Ten-cm long specimen. Scale bar $=10 \mu \mathrm{m}$.

chomycterus spegazzini (Arratia and Veloso 1980, Gonzo et al. 1996), and the sample of Trichomycterus paolence from Jacutinga stream (cytotype B) can be identified. The similar karyotypical macrostructures found in those species plus cytotype B suggest a possible phylogenetic connection, whereas the karyotypic structure $2 n=54$ compound by metacentric and submetacentric chromosomes, probably must be due to some adaptative feature inherited from a common ancestor. The occurrence of subtelocentric pairs in cytotypes A and C also suggests that they could form a cluster with Trichomycterus laucaensis and mainly with the living ancestor lineage, Trichogenes longipinnis.

Lima and Galetti Jr. (1990) pointed out to a symplesiomorphic condition concerning the nucleolar organizer regions (NORs) in the Trichomycteridae family. The phenotype detected in that study consisted in the identification of only one chromosome pair responsible for rDNA synthesis. The analysis of cytotypes A and B showed that the same first chromosome pair in the submetacentric group is responsible for the nucleolus organization, suggesting a close relationship between these two populations and probably to Trichomycterus spegazzini which also presents the same condition (Gonzo et al. 1996). In the cytotype C the NORs were also observed in a single chromosome pair, but they were localized in the interstitial portion of the first metacentric pair. This situation can be characterized as an autapomorphic marker for this population. 


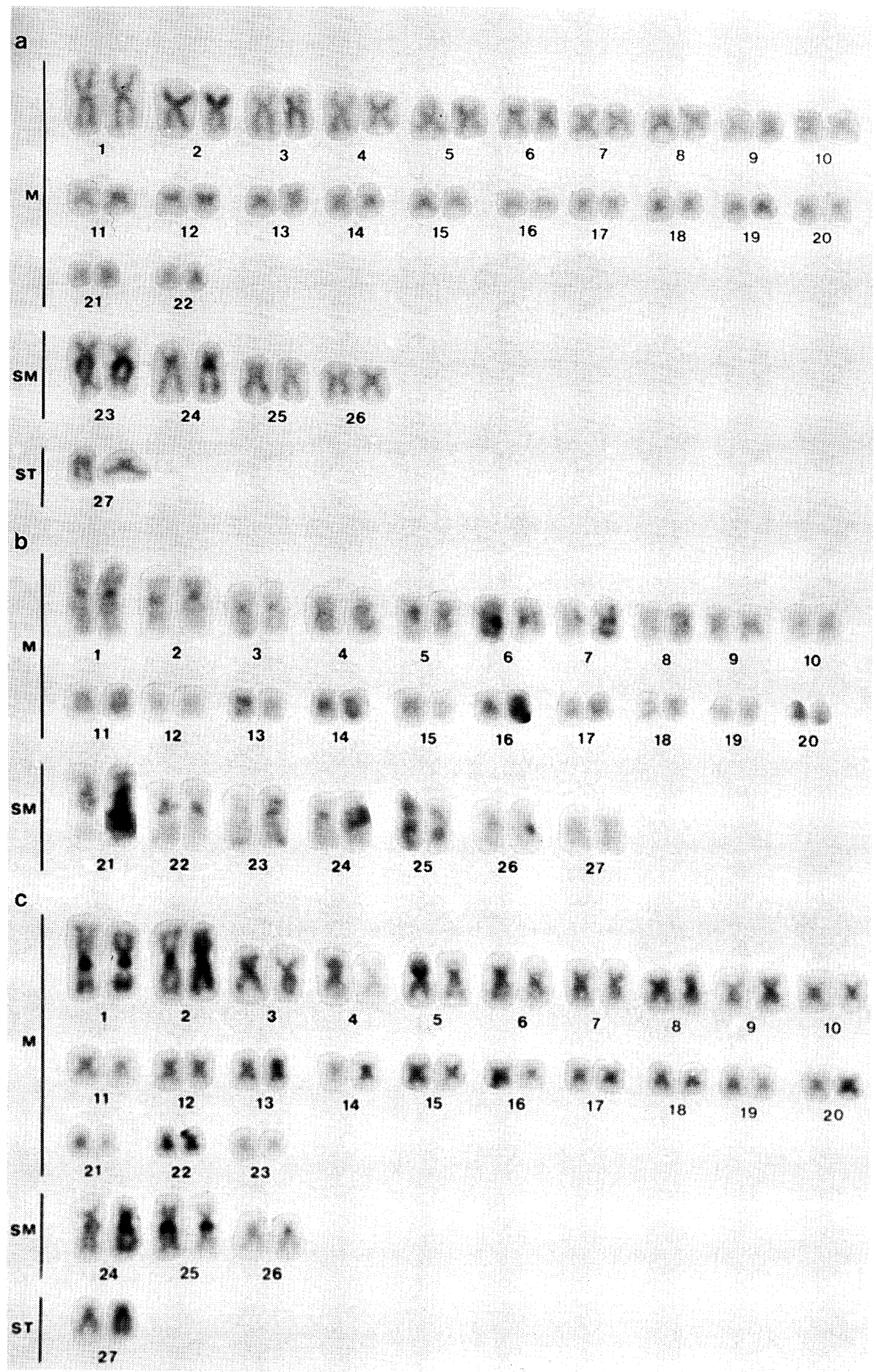

Fig. 4. C-banded karyotypes of Trichomycterus paolence populations showing the distribution of heterochromatin in the chromosomes. Note the heterochromatic blocks associated with the NORs (pair 23 in a) pair 21 in b) and pair 1 in c)). a) cytotype A; b) cytotype B; c) cytotype C. 
Based on the parsimony thinking, the asymmetry in NOR phenotype observed in the cytotypes $\mathrm{A}$ and $\mathrm{B}$ (phenotype 1) and in the cytotype $\mathrm{C}$ (phenotype 2) suggests that the modification of NOR position in the karyotypes was probably due to the occurrence of paracentric inversions involving the long arms of the largest metacentric pair (cytotype C) followed by delections in the short arms and resulting in the phenotype 1 .

The subfamily Trichogeninae is considered by many authors as a basal group in the evolution of Trichomycteridae as a whole. However, the NOR features presented in Trichogenes longipinnis (Lima and Galetti Jr. 1990) led the authors to consider this species as holding an ancestral condition for this character within the group. Thus, if the terminal NOR is considered to be a plesiomorphic condition in Trichogeninae, the interstitial NOR condition detected in the populations of Trichomycterus paolence studied in the present investigation may represent a sinapomorphic condition to the genus as a whole.

The detailed C-banded analysis of the three cytotypes of Trichomycterus paolence revealed that chromosome pairs 1, 2 and 3 of the cytotype B present centromeric heterochromatin blocks, while in the cytotype $C$ the pairs number 1,2 and 5 present pericentromeric bands. In the cytotype A these pairs have no heterochromatic regions except for pair 2, which presents an entirely heterochromatic small arm. Concerning to the submetacentric group, there is a large variability in the number and position of heterochromatic bands in all the populations studied.

Considering the type and distribution of heterochromatic blocks found in Trichogenes longipinnis by Lima and Galetti Jr. (1990) it is infered that a possible tendency of lost of heterochromatin could be involved in the evolutive process of these lineages. While the samples of the Trichomycterus paolence populations here studied presented more centromeric bands, Trichogenes longipinnis presented well characterized large pericentromeric bands.

The present analysis of specific chromosome differences involving three alopatric cytotypes of Trichomycterus paolence, is an attempt to better understand the evolutionary history of this group. However, more extensive taxonomic and phylogenetic studies associate to resolutive cytogenetic and molecular techniques are needed, considering that the family Trichomycteridae is a monophyletic and endemic South American fish group and constitutes a peculiar biological material, that can be used as a speciation model in the superfamily Loricariodea.

\section{Acknowledgements}

The authors are grateful to Mr. Renato Devidé for technical assistance. Grants supporting this study were provided by CNPq, CAPES and FAPESP.

\section{References}

Almeida-Toledo, L. F., Oliveira, C. and Foresti, F. 1993. A Citogenética de Peixes no Brasil. Res. X Encontro Brasileiro de Ictiologia. pp. 347-376.

Andreata, A. A., Almeida-Toledo, L. F., Oliveira, C. and Toledo-Filho, S. A. 1994. Cytogenetic studies on the subfamily Hypoptopomatinae (Pisces, Siluriformes, Loricariidae): III. Analysis of seven species. Caryologia 47: 27-37.

Arratia, G. and Veloso, A. 1980. Cariotipo de peces Trichomicteridos (Siluriformes). Arch. Biol. y Med. Experimentales 13(1): p. 137.

Baskin, J. N. 1973. Structure and relationship of the Trichomycteridae. PhD Thesis, Faculty in Biology, City University of New York.

Burgess, W. E. 1989. An atlas of freshwater and marine catfishes. A preliminary survey of the siluriformes. T.F.H. Publication, Neptune City, Canada 28: 305-325.

Caramaschi, E. P. 1986. Distribuição e ecologia da ictiofauna de riachos des bacias dos rios Tietê e Paranapanema junto ao divisor de águas (Botucatu, SP). Doctoral Thesis. Departamento de Ciências Biológicas. Universidade Federal de São Carlos.

Eigenmann, C. H. 1918. The Pigidiidae, a family of South American catfishes. Mem. Carnegie Mus. 7: 259-398. 
Foresti, F., Almeida-Toledo, L. F. and Toledo-Filho, S. A. 1981. Polymorphic nature of nucleolus organizer regions in fishes. Cytogenet. Cell. Genetic. 31: 137-144.

Gonzo, M. G., Fennochio, A. S. and Pastori, M. C. 1996. Estudios citogeneticos del genero Trichomycterus: Cariotipo, Heterocromatina Constitutiva y NORs de Trichomycterus spegazzini. VI Simp. Citogen. Evol. e Aplic. de Peixes Neotropicais. pp. 72/B. 30.

Howell, W. M. and Black, D. A. 1980. Controlled siliver staining of nucleous organizer regions with a protective colloidal developer: a 1-step method. Experimentia 36: 1014-1015.

Lima, N. R. W. and Galetti Jr., P. M. 1990. Chromosome characterization of the fish Trichogenes longipinnis. A possible basic karyotype of Trichomycteridae. Rev. Brasil. Genetica 13: 239-245.

Nelson, J. S. 1994. Fishes of the World. John Wiley \& Sons, New York, 3rd ed., pp. 168-170.

Oliveira, C., Almeida-Toledo, L. F., Foresti, F., Britski, H. A. and Toledo-Filho, S. A. 1988. Chromosome formula of neotropical freshwater fishes. Rev. Brasil. Genetica 7 (3): 577-624.

Summer, A. T. 1972. A simple technique for demonstrating centromeric heterochromatin. Expl. Cell. Res. 75: 304-306. 